\title{
Catalases may Play Different Roles in Influencing Resistance to Virus-induced Hypersensitive Necrosis
}

\author{
O. VICZIÁN*, A. KÜNSTLER*, Y. M. HAFEZ¹ and L. KIRÁLY*** \\ Plant Protection Institute, Centre for Agricultural Research, Hungarian Academy of Sciences, \\ H-1525 Budapest, P.O.B. 102, Hungary \\ ${ }^{1}$ Present address of Y.M. Hafez: Department of Agricultural Botany, Plant Pathology Branch, \\ Faculty of Agriculture, Kafr-El-Sheikh University, 33516, Kafr-El-Sheikh, Egypt
}

(Received: 7 July 2014; accepted: 16 July 2014)

\begin{abstract}
High concentrations of the reactive oxygen species (ROS) superoxide $\left(\mathrm{O}_{2}{ }^{-}\right)$and hydrogen peroxide $\left(\mathrm{H}_{2} \mathrm{O}_{2}\right)$ contribute to the induction of plant cell and tissue death (necrosis). In an effort to create transgenic plants with high antioxidant capacity that could resist necrotic symptoms we produced two transgenic tobacco (Nicotiana tabacum cv. SR1) lines (S1 and S2) overexpressing a tomato chloroplast superoxide dismutase (SlChSOD). SOD genes encode for antioxidant enzymes that dismutate superoxide to hydrogen peroxide. Therefore, SOD-overproducing plants may contain high levels of hydrogen peroxide and are sensitive to stress-related necrosis unless sufficient degradation of hydrogen peroxide is conferred by elevated expression of antioxidants like e.g. catalases and peroxidases. Indeed, line S1 displayed elevated expression of a glutathione peroxidase $(N t G P X)$ and a glutathione S-transferase (NtGSTU1b), as compared to wild type plants. Interestingly, however, expression of a catalase (NtCAT1) was repressed in both SOD-overexpressing lines. This predicts that such plants could be sensitive to localized necrosis (HR) caused by virus infection, since repression of NtCAT1 has been shown to occur during virus-induced HR (e.g. Dorey et al., 1998; Künstler et al., 2007). To elucidate whether other catalases might play a role in resistance to virus induced HR-type necrotic symptoms, a maize catalase ( $\mathrm{ZmCat}$ ) was transiently overexpressed in Nicotiana edwardsonii and $N$. edwardsonii var. Columbia plants by agroinfiltration. Inoculation of agroinfiltrated plants with Tobacco mosaic virus (TMV) revealed that ZmCat 2 confers enhanced resistance to HR-type necrosis during TMV infection. It seems that catalases may play different roles in influencing resistance to virus-induced hypersensitive necrosis.
\end{abstract}

Keywords: reactive oxygen species, antioxidants, superoxide dismutase, catalase, hypersensitive necrosis, Tobacco mosaic virus.

In plants, pathogenic infections and abiotic stresses are frequently associated with accumulation of reactive oxygen species (ROS) like superoxide $\left(\mathrm{O}_{2}^{-{ }^{-}}\right)$and hydrogen peroxide $\left(\mathrm{H}_{2} \mathrm{O}_{2}\right)$. High ROS levels induce oxidative stress ultimately resulting in cell and tissue death (necrosis) (e.g. Doke and Ohashi, 1988; Ádám et al., 1989; Levine et al., 1994; Jabs et al., 1996; Karpinski et al., 1999; Mittler, 2002; Hernandez et al., 2004; Torres et al., 2006). Under natural conditions the up-regulation of antioxidant defense systems seems to be a general response to oxidative stress. Often this is the only evidence that oxidative stress has occurred in vivo (Halliwell and Gutteridge, 1999). Antioxidant defense includes non-enzymatic scavengers and low molecular weight compounds such as ascorbic acid

*O. Viczián and A. Künstler contributed equally to this work and are considered co-first authors.

** Corresponding author; e-mail: kiraly.lorant@agrar.mta.hu 
(ASC), glutathione (GSH) and phenols. Enzymatic ROS scavengers include antioxidant enzymes like superoxide dismutase (SOD), catalase (CAT) and enzymes related to ascorbate and glutathione metabolism (e.g. ascorbate peroxidase, dehydroascorbate reductase, monodehydroascorbate reductase, glutathione reductase, glutathione peroxidase, and glutathione S-transferase) (Noctor and Foyer, 1998; Asada, 1997, 1999; Foyer and Noctor, 2011; Heyneke et al., 2013).

SOD genes encode for antioxidant enzymes that dismutate superoxide to hydrogen peroxide, while degradation of hydrogen peroxide is conferred by elevated expression of e.g. catalases and peroxidases (Tsang et al., 1991; Bowler et al., 1992; Mittler, 2002). The balance between the activity of SOD and $\mathrm{H}_{2} \mathrm{O}_{2}$-degrading antioxidant enzymes (e.g. CAT or ascorbate peroxidase) is crucial for controlling the steady-state levels of ROS and the development of plant cell death (see e.g. Mittler et al., 1998). Transgenic antisense tobacco plants with reduced CAT or ascorbate peroxidase (APX) expression develop spontaneous necrotic lesions and display increased sensitivity to cell death during bacterial infection (Chamnongpol et al., 1996; Takahashi et al., 1997; Mittler et al., 1999). This implies that increases in SOD expression alone may not be sufficient to counteract oxidative damage and necrosis, due to the accumulation of $\mathrm{H}_{2} \mathrm{O}_{2}$. Indeed, transgenic SOD-overexpressing tobacco that is tolerant to necrosis caused by high light intensity and low temperature, also displays elevated levels of endogenous APX (Sen Gupta et al., 1993). Transgenic plants that simultaneously overexpress a SOD and an APX gene show enhanced tolerance to necrosis caused by various abiotic stresses and pathogenic infections (Kwon et al., 2002; Tang et al., 2006; Lee et al., 2007; Faize et al., 2011, 2012; Diaz-Vivancos et al., 2013).

In an effort to create transgenic plants with high antioxidant capacity that could resist necrotic symptoms, a preliminary analysis of two transgenic tobacco (Nicotiana tabacum cv. SR1) lines overexpressing a tomato chloroplast superoxide dismutase ( $\mathrm{SlCh}$ $S O D$ ) is presented. Differential expression of genes encoding $\mathrm{H}_{2} \mathrm{O}_{2}$-degrading antioxidant enzymes occurred in both SOD-overexpressing lines. Notably, expression of a catalase (NtCAT1) known to be down-regulated during virus-induced localized necrosis (HR) (Dorey et al., 1998; Yi et al., 1999, 2003; Künstler et al., 2007) was repressed in healthy, SOD-transgenic tobaccos, predicting that such plants could be sensitive to localized necrosis caused by virus infection. To investigate whether other catalases might play a role in resistance to virus induced HR-type necrosis, a maize catalase (ZmCat2) was transiently overexpressed in Nicotiana edwardsonii and N. edwardsonii var. Columbia plants by agroinfiltration.

\section{Materials and Methods}

\section{Plants and pathogens}

Nicotiana tabacum cv. Samsun nn, cv. SR1, Nicotiana edwardsonii and N. edwardsonii var. Columbia plants were grown under normal greenhouse conditions $\left(18-23{ }^{\circ} \mathrm{C}\right.$, ca. $160 \mu \mathrm{mol} / \mathrm{m}^{2} / \mathrm{s}$ supplemental light for 8 hours/day, $75-80 \%$ relative humidity). 
The U1 strain of Tobacco mosaic virus (TMV) was maintained on N. tabacum cv. Samsun nn. For mechanical virus inoculation the sap of TMV-infected leaves homogenized in tap water was rubbed onto leaves of healthy plants with carborundum as an abrasive. 60-70 days old plants were used for all experiments.

Agrobacterium tumefaciens LBA4404 was maintained on solid yeast extract peptone (YEP) medium with $50 \mu \mathrm{g} / \mathrm{ml}$ rifampicin and $50 \mu \mathrm{g} / \mathrm{ml}$ streptomycin. A. tumefaciens LBA4404 containing binary vectors pBB31S or pBB30Cat that carry a tomato chloroplast superoxide dismutase $(S l C h S O D)$ and a maize catalase 2 (ZmCat2), respectively, were maintained on the same medium including $50 \mu \mathrm{g} / \mathrm{ml}$ kanamycin as well.

\section{Plant transformation}

Transformation of N. tabacum cv. SR 1 plants with SlChSOD was conducted essentially as described by Horsch et al. (1985) with modifications. Sterilized leaf discs one cm in diameter were dipped in a liquid culture of A. tumefaciens LBA4404 pBB31S resuspended in Murashige-Skoog (MS) medium and transferred to solid MS medium for two days. Afterwards, leaf discs were washed with sterile distilled water containing $500 \mu \mathrm{g} / \mathrm{ml}$ cefotaxim to eliminate A. tumefaciens and then transferred to callus-inducing medium containing $200 \mu \mathrm{g} / \mathrm{ml}$ cefotaxim and $50 \mu \mathrm{g} / \mathrm{ml}$ bialaphos to select for transformant plant calli. Shoot regenerated from calli within ca. three weeks were transferred to a similar medium (containing only $50 \mu \mathrm{g} / \mathrm{ml}$ bialaphos) for rooting. Intact, grown plants were transferred to pots containing sterile soil and later moved to the greenhouse. PCR analysis detected the SlChSOD transgene in two such plants (T0 generation, S1 and S2) which were also used for gene expression assays and subsequently grown to maturity to produce T1 seeds and establish lines S1 and S2.

\section{PCR analysis for transgene detection in bacteria and plants}

The presence of the SlChSOD and ZmCat2 transgenes in Agrobacterium tumefaciens LBA4404 pBB31S and pBB30Cat, respectively, was checked by polymerase chain reaction (PCR). To prepare bacterial template DNA for PCR, $100 \mu \mathrm{l}$ of $2 \mathrm{ml}$ bacterial cultures grown for two days at $28{ }^{\circ} \mathrm{C}$ in liquid YEP medium were briefly centrifuged and resuspended in an equal volume of sample buffer $\left(2.5 \mathrm{mg} / \mathrm{ml} \mathrm{Na}_{3} \mathrm{~N}, 2 \%\right.$ Triton $\mathrm{X}-100$, $0.1 \mathrm{M}$ Tris, $\mathrm{pH}$ 8.1). Samples were then kept at $99{ }^{\circ} \mathrm{C}$ for 15 minutes and centrifuged again. $1 \mu \mathrm{l}$ of each supernatant was used in PCR reactions.

The presence of the SlChSOD transgene in bialaphos-resistant transformed and regenerated $N$. tabacum cv. SR1 plants was also verified by PCR analysis. Plant genomic DNA was extracted from ca. $0.1 \mathrm{~g}$ leaf material homogenized in liquid nitrogen with a plant DNA extraction minicolumn kit according to instructions of the manufacturer (Viogene, Sunnyvale, CA, USA).

Semiquantitative PCR for detection of the SlChSOD and ZmCat2 transgenes in A. tumefaciens and N. tabacum cv. SR1 was conducted with reagents supplied by Thermo Fisher Scientific Inc. (Waltham, MA, USA), always using $1 \mu \mathrm{l}$ of template DNA in a total 
reaction volume of $25 \mu \mathrm{l}$, according to instructions of the manufacturer. PCR reactions were carried out with a PTC 200 DNA Engine (MJ Research, Waltham, MA, USA).

Oligonucleotide primers used in PCR reactions were the following: 5'-GGGTGG CCATGAACTCAGTCT-3' (5' primer [forward]) corresponding to a tomato chloroplastic SOD (SlChSOD) sequence (GenBank X14041) and 5'-CATCGCAAGACCGGCAACAGG-3' (3' primer [reverse]) corresponding to an A. tumefaciens nopaline synthase terminator sequence $(t-N O S)$ (GenBank AF434753) giving a 200 bp transgene PCR product; 5'-GGGTCGACGCGCTCTCCGACC-3' (5' primer) corresponding to a maize catalase 2 (ZmCat2) sequence (GenBank J02976) and the $3^{\prime} t$-NOS primer as above, giving a $260 \mathrm{bp}$ transgene PCR product.

\section{RT-PCR analysis for plant gene expression assays}

To prepare samples from wild type and transgenic $N$. tabacum cv. SR1 plants for gene expression analysis, total RNA was extracted from ca. $0.1 \mathrm{~g}$ leaf material homogenized in liquid nitrogen with a plant RNA extraction minicolumn kit according to instructions of the manufacturer (Viogene, Sunnyvale, CA, USA). Gene expression was assayed by a two step reverse transcription polymerase chain reaction (RT-PCR) procedure following the manufacturers' instructions (Thermo Fisher Scientific Inc., Waltham, MA, USA). In the RT step (i.e., first-strand cDNA synthesis), an oligo(dT) primer was used. In the PCR step, relatively low cycle numbers (22-28 cycles) were applied to maintain initial differences in target transcript amounts as much as possible. PCR reactions were carried out in a PTC 200 DNA Engine (MJ Research, Waltham, MA, USA). Expression of a tobacco actin gene (GenBank X69885) served as a reference (constitutive control) of gene expression.

Oligonucleotide primers used in the PCR step of RT-PCR reactions were the following: 5'-CGGAATCCACGAGACTACATAC-3' (5' primer) and 5'-GGGAAGCCAAGATAGAGC-3' (3' primer) for a 230 bp tobacco actin (NtAct) cDNA fragment (GenBank X69885); 5'-TGGACTTCACGGGTTTCAT-3' (5' primer) and 5'-CACCCTTTCCGAGGTCATCC-3' (3' primer) for a 269 bp tomato chloroplastic SOD (SlChSOD) cDNA fragment (GenBank X14041); 5'-GCCGTCCTTAGCAGCAGT-3' (5' primer) and 5'-ACAAGCAACCCTTCCACC-3' (3' primer) for a $420 \mathrm{bp} \mathrm{N}$. plumbaginifolia and putative tobacco SOD (NtSOD) cDNA fragment (GenBank X55974 and EU123521); 5'-TCCGCTTGATGTGACTAAA-3' (5' primer) and 5'-TCCACCCACCGACGAATA-3' (3' primer) for a 501-bp $N$. glutinosa and tobacco catalase 1 (NtCAT1) cDNA fragment (GenBank AF006067, U93244 and HF564632); 5'-TTTAGYCRYAGAGTTGARTGG-3' (5' primer) and 5'-ATTTSCARCMATATCAGC-3' (3' primer) for a 426-bp tobacco tau class glutathione S-transferase (NtGSTU1b) cDNA fragment (degenerate primers based on tobacco, N. benthamiana and potato sequences, GenBank X56263, X56264, X56265, AY206006 and J03679); 5'-CTCCTCCGATTCCAACAG-3' (5' primer) and 5'-GAGCAGCATTATCAC CATTC-3' (3' primer) for a 423 bp tobacco glutathione peroxidase (NtGPX) cDNA fragment (GenBank AB041518). 


\section{Agroinfiltration}

A. tumefaciens LBA4404 pBB30Cat that carries a maize catalase 2 (ZmCat2) was used for agroinfiltration of Nicotiana edwardsonii and N. edwardsonii var. Columbia plants two days before TMV inoculation. Prior to agroinfiltration, the presence of the $\mathrm{ZmCat} 2$ transgene in the bacterium was verified by PCR as described above. Agroinfiltration was done essentially as described by Van der Hoorn et al. (2000) with modifications. $5 \mathrm{ml}$ bacterial cultures grown overnight at $28^{\circ} \mathrm{C}$ in liquid YEP medium (supplemented with $50 \mu \mathrm{g} / \mathrm{ml}$ rifampicin, $50 \mu \mathrm{g} / \mathrm{ml}$ streptomycin and $50 \mu \mathrm{g} / \mathrm{ml}$ kanamycin) were briefly centrifuged, resuspended in $50 \mathrm{ml}$ YEB (yeast extract beef) medium and grown again overnight at $28{ }^{\circ} \mathrm{C}$. This $50 \mathrm{ml}$ bacterial culture was again briefly centrifuged and resuspended in $25 \mathrm{ml}$ infiltration medium (10 mM Mg SO, $10 \mathrm{mM}$ MES, pH 5.6). Acetosyringone (4'-hydroxy-3',5'-dimethoxyacetophenone, Sigma-Aldrich Corp., St. Louis, MO, USA) was added to $200 \mu \mathrm{M}$ and the culture was shaken (100 rpm) at room temperature for ca. 1 hour. Leaves were infiltrated with the bacterial suspension with a syringe and needle as described by Hagborg (1970).

\section{Results}

Transformation of tobacco (Nicotiana tabacum cv. SR1) with a tomato chloroplast superoxide dismutase (SlChSOD) gene yielded several bialaphos-resistant intact plants. PCR analysis confirmed the presence of the SlChSOD transgene in two such plants (T0 generation) designated S1 and S2 with a habit identical to that of wild type (non-transformed) SR1. Although in S2 the size of the PCR product was larger than the expected 200 bp (Fig. 1), gene expression analysis by RT-PCR revealed presence of the same $\mathrm{SlCh}$ $S O D$-specific mRNA species in both $\mathrm{S} 1$ and $\mathrm{S} 2$ tobaccos. In addition, transgenic and wild type tobaccos expressed an endogenous $S O D$ gene (NtSOD) to similar high levels (Fig. 1).

It can be anticipated that SOD-overproducing plants contain high levels of $\mathrm{H}_{2} \mathrm{O}_{2}$ and are sensitive to stress-related necrosis unless sufficient $\mathrm{H}_{2} \mathrm{O}_{2}$-degradation is conferred by elevated expression of antioxidants like e.g. catalases and peroxidases. Indeed, S1 tobacco displayed elevated expression of an endogenous glutathione peroxidase (NtGPX) and a tau class glutathione S-transferase $(N t G S T U 1 b)$, as compared to wild type plants (Fig. 2). Interestingly, however, expression of a catalase (NtCAT1) was repressed in both SOD-overexpressing plants (Fig. 2). Repression of NtCAT1 has been also shown to occur during virus-induced HR (Dorey et al., 1998; Yi et al., 1999, 2003; Künstler et al., 2007) suggesting that this catalase may not play a role in reducing localized necrosis during virus infections.

In order to investigate whether catalases other than NtCAT1 might play a role in resistance to virus induced HR-type necrotic symptoms, a maize catalase ( $\mathrm{ZmCat} 2$ ) was transiently overexpressed in Nicotiana edwardsonii and N. edwardsonii var. Columbia plants by agroinfiltration. We have chosen these two interspecific hybrid tobaccos because our earlier research showed that var. Columbia displays enhanced resistance to HRtype necrosis induced by e.g. Tobacco mosaic virus (TMV), as compared to N. edward- 
SlChSOD

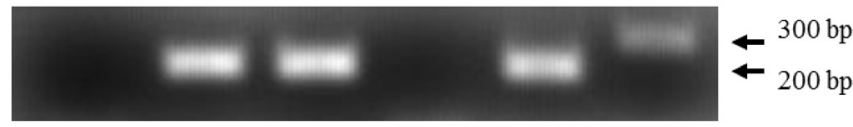

\section{$\begin{array}{llllll}\text { PCR0 At/S At/S SR1 S1 } & \text { S2 }\end{array}$}

SIChSOD

NtSOD
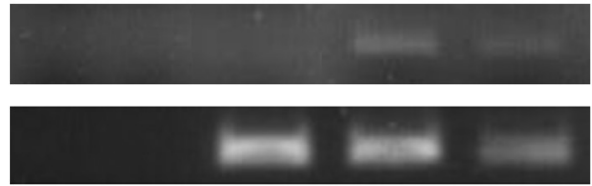

RT-PCR

NtAct

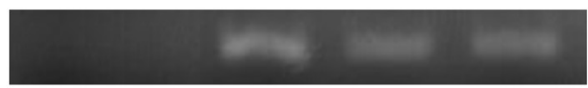

\section{$\begin{array}{llll}\text { PCR0 RT0 } & \text { SR1 } & \text { S1 } & \text { S2 }\end{array}$}

Fig. 1. Incorporation of a tomato chloroplast superoxide dismutase (SlChSOD) transgene into Nicotiana tabacum cv. SR1 (T0 generation, S1 and S2 lines) and expression of its mRNA as verified by

polymerase chain reaction (PCR) and reverse transcription-PCR, respectively. NtSOD= expression of an endogenous $S O D$ gene in wild type (non-transformed) and transgenic tobaccos. For RT-PCR, a tobacco actin gene $(N t A c t)$ served as a reference. RT0 = negative control of reverse transcription (no RNA template). PCR0 = negative control of polymerase chain reaction (no DNA template). $\mathrm{At} / \mathrm{S}=$ presence of SlChSOD in Agrobacterium tumefaciens LBA4404 pBB31S used for plant transformation. SR1 = absence of SlChSOD in non-transformed tobacco. Arrows depict sizes of PCR-amplified fragments of SlChSOD (bp = base pairs)

NtCAT1

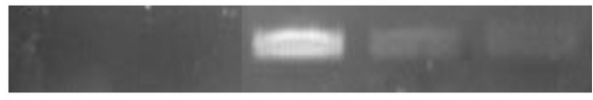

NtGSTU1b

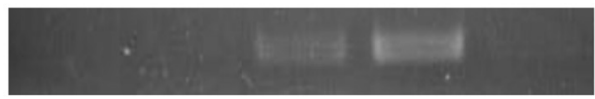

$N t G P X$

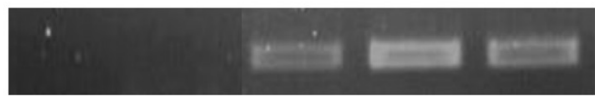

NtAct

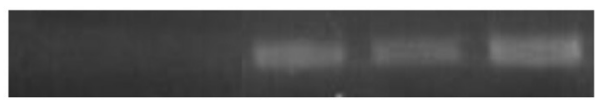

PCRO RTO SR1 S1 S2

Fig. 2. Changes in expression of genes encoding $\mathrm{H}_{2} \mathrm{O}_{2}$-degrading antioxidant enzymes in tobacco plants expressing a tomato chloroplast superoxide dismutase (SlChSOD) transgene (Nicotiana tabacum cv.

$\mathrm{SR} 1, \mathrm{~T} 0$ generation, $\mathrm{S} 1$ and $\mathrm{S} 2$ lines). $N t C A T 1=$ catalase $1 . N t G S T U 1 b=$ tau class glutathione S-transferase. $N t G P X=$ glutathione peroxidase. Gene expression was analyzed by RT-PCR, a tobacco actin gene $(N t A c t)$ served as a reference. RT0 = negative control of reverse transcription

(no RNA template). $\mathrm{PCR} 0=$ negative control of polymerase chain reaction (no DNA template).

SR1 = non-transformed tobacco 
sonii (Cole et al., 2004). Inoculation of agroinfiltrated plants with TMV revealed that ZmCat2 confers enhanced resistance to HR-type necrosis during TMV infection in both N. edwardsonii and N. edwardsonii var. Columbia. Transient overexpression of this catalase reduced the number of TMV-induced HR-type necrotic lesions and total necrotized leaf area by at least $40-50 \%$ (Fig. 3). It is worth mentioning that in TMV-inoculated $N$. edwardsonii leaves agroinfiltration of $\mathrm{ZmCat} 2$ reduced the necrotized leaf area to ca. the extent found in TMV-inoculated and control-infiltrated (A. tumefaciens, without ZmCat2) var. Columbia leaves, while ZmCat 2 was able to further reduce the extent of TMV-induced HR-type necrotization in var. Columbia (Fig. 3).

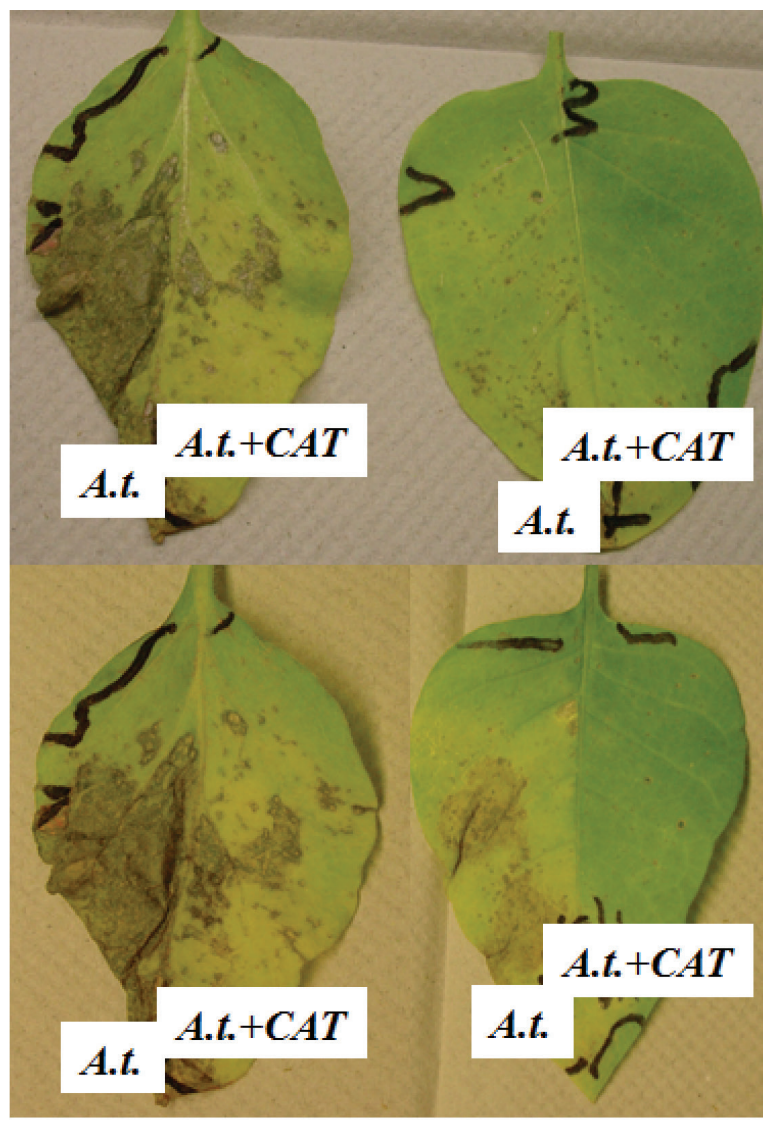

\section{N. edwardsonii}

N. e. var. Columbia

Fig. 3. Transient overexpression of a maize catalase gene (ZmCat2, "CAT") by agroinfiltration in Nicotiana edwardsonii and N. edwardsonii var. Columbia; effect on localized necrosis (HR) caused by Tobacco mosaic virus (TMV) in inoculated leaves. Left leaf halves: control-infiltrated (Agrobacterium tumefaciens LBA4404, without ZmCat2). Right leaf halves: infiltrated with A. tumefaciens LBA4404 carrying ZmCat2. Plants were inoculated with TMV two days after agroinfiltration. Photos in the upper and lower panels were taken six and seven days after TMV inoculation, respectively 


\section{Discussion}

In an effort to create transgenic plants with high antioxidant capacity that could resist necrotic symptoms we produced two transgenic tobacco (Nicotiana tabacum cv. $\mathrm{SR} 1$ ) lines (S1 and S2) overexpressing a tomato chloroplast superoxide dismutase ( $\mathrm{SlCh}$ $S O D)$. This SOD gene has been shown to confer enhanced tolerance of transgenic potato shoots and roots to tissue necrosis caused by the superoxide-generating herbicide, paraquat (Perl-Treves et al., 1988; Perl et al., 1993). Our preliminary analysis of Nicotiana tabacum cv. SR1 S1 and S2 plants might indicate a similar tolerance to necrotic symptoms caused by abiotic stresses and pathogen infections. Although in planta overexpression of $S O D$ genes often increase endogenous $\mathrm{H}_{2} \mathrm{O}_{2}$ levels, such plants are less sensitive to stress-related necrosis if sufficient $\mathrm{H}_{2} \mathrm{O}_{2}$-degradation is conferred by elevated expression of antioxidants like e.g. catalases and peroxidases (Kwon et al., 2002; Tang et al., 2006; Lee et al., 2007; Faize et al., 2011, 2012; Diaz-Vivancos et al., 2013). We found that $\mathrm{S} 1$ tobacco indeed displays elevated expression of an endogenous glutathione peroxidase $(N t G P X)$ and a tau class glutathione S-transferase (NtGSTU1b), genes that may take part in the degradation of $\mathrm{H}_{2} \mathrm{O}_{2}$ and lipid hydroperoxides during oxidative stress. GST isoenzymes are encoded by a gene family divided into different classes based on sequence similarities and biochemical function (Edwards et al., 2000; Wagner et al., 2002). Most GSTs belong to the phi and theta classes and participate in detoxification reactions by catalyzing the conjugate formation between electrophilic compounds and the antioxidant glutathione (GSH) (Wagner et al., 2002; Dixon and Edwards, 2009a; Dixon et al., 2011). However, certain tau class GSTs possess a glutathione-peroxidase activity and are able to catalyze the breakdown of $\mathrm{H}_{2} \mathrm{O}_{2}$ and lipid hydroperoxides (Bartling et al., 1993; Dixon et al., 2009b). In fact, overexpression of GSTs with both GST and GPX activity conferred enhanced tolerance of tobacco to paraquat and thermal or salt stress (Roxas et al., 1997; Yu et al., 2003).

Although two genes that may encode $\mathrm{H}_{2} \mathrm{O}_{2}$-degrading enzymes ( $N t G P X$ and $N t G$ $S T U 1 b)$ were induced in our SOD-overexpressing S1 tobacco, this was not the case with an endogenous catalase gene. Notably, expression of a class 1 catalase (NtCAT1) was repressed in both healthy, SOD-transgenic tobaccos. It appears that in plants stressed by pathogenic infections or chemical treatments class 1 catalases are often repressed (Williamson and Scandalios, 1992; Willekens et al., 1994), although their original function is the removal of $\mathrm{H}_{2} \mathrm{O}_{2}$ produced during photorespiration in leaf peroxisomes (Willekens et al., 1995). For example, NtCAT1 was shown to be down-regulated during virus-induced localized necrosis (HR) in several Nicotiana species (Dorey et al., 1998; Yi et al., 1999, 2003; Künstler et al., 2007). Repression of NtCAT1 in virus-inoculated leaves that display HR is usually transient and begins within the first 24 hours after inoculation by TMV or Tobacco necrosis virus (TNV). It was also shown that NtCAT1 is repressed in the vicinity of necrotic lesions (Dorey et al., 1998; Yi et al., 1999) suggesting a role for this gene primarily in the induction, rather than elimination of necrosis during localized virus infections. However, CAT1 may play different roles in systemic virus infections: a recent report indicates that a tomato CAT1 gene confers Pepino mosaic virus (PepMV) accumulation during systemic movement (Mathioudakis et al., 2013). Based on the above-mentioned 
data, repression of NtCAT1 in healthy, SOD-transgenic S1 and S2 tobaccos predicts that these plants could be sensitive to localized necrosis caused by virus infection.

In order to elucidate whether catalases other than NtCAT1 might play a role in resistance of Nicotiana species to virus induced HR-type necrosis, transient in planta expression of a maize class 2 catalase ( $\mathrm{ZmCat} 2$ ) was tested. Class 2 catalases are usually stimulated during abiotic and biotic stresses. For example, a potato CAT2 gene is induced locally and systemically upon nematode and bacterial infection (Niebel et al., 1995). Furthermore, in tobacco displaying virus-induced HR CAT2 is only slightly repressed in tissues close to necrotic lesions (Dorey et al., 1998). Also, CAT2 mRNA levels are rapidly induced during oxidative damage by ozone, sulfur dioxide and UV-B radiation (Willekens et al., 1994). Together, these results point to a pivotal role of class 2 catalases in defense against various environmental (oxidative) stresses (Willekens et al., 1995; Vanderauwera et al., 2011). In this study, we have shown that transient overexpression of ZmCat2 in Nicotiana edwardsonii and N. edwardsonii var. Columbia indeed confers enhanced resistance to HR-type necrosis during TMV infection. Previously we have demonstrated that N. edwardsonii is more susceptible to HR-type necrosis induced by e.g. Tobacco mosaic virus (TMV), than N. edwardsonii var. Columbia (Cole et al., 2004). Interestingly, in TMV-infected $N$. edwardsonii transient ZmCat2 expression reduced the necrotized leaf area to ca. the extent displayed by var. Columbia plants. Our results suggest that certain endogenous class 2 catalases may contribute to the enhanced resistance of $N$. edwardsonii var. Columbia to virus-induced HR-type necrosis.

\section{Acknowledgements}

The help of Dr. Sándor Süle in production of transgenic tobacco lines is gratefully acknowledged. Agrobacterium tumefaciens LBA4404 pBB31S and pBB30Cat was a kind gift of Dr. János Györgyey (Biological Research Centre, Hungarian Academy of Sciences). This research was supported by grants of the Hungarian Scientific Research Fund (OTKA K84002 and PD108455).

\section{Literature}

Asada, K. (1997): The role of ascorbate peroxidase and monodehydroascorbate reductase in $\mathrm{H}_{2} \mathrm{O}_{2}$ scavenging in plants. In: J. G. Scandalios (ed.): Oxidative Stress and Molecular Biology of Antioxidant Defences. Cold Spring Harbor Laboratory Press, Cold Spring Harbor, NY, pp. 715-735.

Asada, K. (1999): The water-water cycle in chloroplasts: scavenging of active oxygen and dissippation of excess photons. Annu. Rev. Plant Physiol. Plant Mol. Biol. 50, 601-639.

Ádám, A., Farkas, T., Somlyai, G., Hevesi, M. and Király, Z. (1989): Consequence of $\mathrm{O}_{2}{ }^{--}$generation during a bacterially induced hypersensitive reaction in tobacco: deterioration of membrane lipids. Physiol. Molec. Plant Pathol. 34, 13-26.

Bartling, D., Radzio, R., Steiner, U. and Weiler, E. W. (1993): A glutathione-S-transferase with glutathione peroxidase activity from Arabidopsis thaliana. Molecular cloning and functional characterization. Eur. J. Biochem. 216, 579-586.

Bowler, C., Van Montagu, M. and Inzé, D. (1992): Superoxide dismutase and stress tolerance. Annu. Rev. Plant Physiol. Plant Mol. Biol. 43, 83-116. 
Chamnongpol, S., Willekens, H., Langebartels, C., Van Montagu, M., Inzé, D. and Van Camp, W. (1996): Transgenic tobacco with a reduced catalase activity develops necrotic lesions and induces pathogenesis-related expression under high light. Plant J. 10, 491-503.

Cole, A. B., Király, L., Lane, L. C., Wiggins, E. B., Ross, K. and Schoelz, J. E. (2004): Temporal expression of PR-1 and enhanced mature plant resistance to virus infection is controlled by a single dominant gene in a new Nicotiana hybrid. Mol. Plant-Microbe Interact. 17, 976-985.

Diaz-Vivancos, P., Faize, M., Barba-Espín, G., Faize, L., Petri, C., Hernández, J. A. and Burgos, L. (2013): Ectopic expression of cytosolic superoxide dismutase and ascorbate peroxidase leads to salt stress tolerance in transgenic plums. Plant Biotechnol. J. 11, 976-985.

Dixon, D. P. and Edwards, R. (2009a): Selective binding of glutathione conjugates of fatty acid derivatives by plant glutathione transferases. J. Biol. Chem. 284, 21249-21256.

Dixon, D. P., Hawkins, T., Hussey, P. J. and Edwards, R. (2009b): Enzyme activities and subcellular localization of members of the Arabidopsis glutathione transferase superfamily. J. Exp. Bot. 60, 1207-1218.

Dixon, D. P., Sellars, J. D. and Edwards, R. (2011): The Arabidopsis phi class glutathione transferase AtGSTF2: binding and regulation by biologically active heterocyclic ligands. Biochem. J. 438, 63-70.

Doke, N. and Ohashi, Y. (1988): Involvement of an $\mathrm{O}_{2}{ }^{-}-$generating system in the induction of necrotic lesions on tobacco leaves infected with Tobacco mosaic virus. Physiol. Molec. Plant Pathol. 32, 163-175.

Dorey, S., Baillieul, F., Saindrenan, P., Fritig, B. and Kaufmann, S. (1998): Tobacco class I and II catalases are differentially expressed during elicitor-induced hypersensitive cell death and localized acquired resistance. Mol. Plant-Microbe Interact. 11, 1102-1109.

Edwards, R., Dixon, D. and Walbot, B. (2000): Plant glutathione S-transferases: enzymes with multiple functions in sickness and in health. Trends Plant Sci. 5, 193-198.

Faize, M., Burgos, L., Faize, L., Piqueras, A., Nicolas, E., Barba-Espín, G., Clemente-Moreno, M. J., Alcobendas, R., Artlip, T. and Hernandez, J. A. (2011): Involvement of cytosolic ascorbate peroxidase and Cu/ Zn-superoxide dismutase for improved tolerance against drought stress. J. Exp. Bot. 62, 2599-2613.

Faize, M., Burgos, L., Faize, L., Petri, C., Barba-Espín, G., Diaz-Vivancos, P., Clemente-Moreno, M. J., Alburquerque, N. and Hernandez, J. A. (2012): Modulation of tobacco bacterial disease resistance using cytosolic ascorbate peroxidase and $\mathrm{Cu}, \mathrm{Zn}$-superoxide dismutase. Plant Pathol. 61, 858-866.

Foyer, C. H. and Noctor, G. (2011): Ascorbate and glutathione: the heart of the redox hub. Plant Physiol. 155, 2-18.

Hagborg, W. A. F. (1970): A device for injecting solutions and suspensions into thin leaves of plants. Can. J. Bot. 48, 1135-1136.

Halliwell, B. and Gutteridge, J. M. C. (1999): Free Radicals in Biology and Medicine. Oxford University Press, Inc., New York.

Hernandez, J. A., Escobar, C., Creissen, G. and Mullineaux, P. (2004.): Role of hydrogen peroxide and the redox state of ascorbate in the induction of antioxidant enzymes in pea leaves under excess light stress. Functional Plant Biology 31, 359-368.

Heyneke, E., Luschin-Ebengreuth, N., Krajcer, I., Wolkinger, V., Müller, M. and Zechmann, B. (2013): Dynamic compartment specific changes in glutathione and ascorbate levels in Arabidopsis plants exposed to different light intensities. BMC Plant Biology 13, 104-122.

Horsch, R. B., Fry, J. E., Hoffmann, N. L., Eichholtz, D., Rogers, S. G. and Fraley, R. T. (1985): A simple and general method for transferring genes into plants. Science 227, 1229-1231.

Jabs, T., Dietrich, R. A. and Dangl, J. L. (1996): Initiation of runaway cell death in an Arabidopsis mutant by extracellular superoxide. Science 273, 1853-1856.

Karpinski, S., Reynold, H., Karpinska, B., Wingsle, G. and Mullineaux, P. M. (1999): Systemic signaling and acclimation in response to excess excitation energy in Arabidopsis. Science 284, 654-657.

Künstler, A., Hafez, Y. M. and Király, L. (2007): Transient suppression of a catalase and an alternative oxidase gene during virus-induced local lesion formation (hypersensitive response) is independent of the extent of leaf necrotization. Acta Phytopathol. et Entomol. Hung. 42, 185-196.

Kwon, S. Y., Jeong, Y. J., Lee, H. S., Kim, J. S., Cho, K. Y., Allen, R. D. and Kwak, S. S. (2002): Enhanced tolerances of transgenic tobacco plants expressing both superoxide dismutase and ascorbate peroxidase in choroplasts against methyl viologen-mediated oxidative stress. Plant Cell Environ. 25, 873-882. 
Lee, Y.-P., Kim, S. H., Bang, J. W., Lee, H. S., Kwak, S. S. and Kwon, S. Y. (2007): Enhanced tolerance to oxidative stress in transgenic tobacco plants expressing three antioxidant enzymes in chloroplasts. Plant Cell Rep. 26, 591-598.

Levine, A., Tenhaken, R., Dixon, R. and Lamb, C. (1994): $\mathrm{H}_{2} \mathrm{O}_{2}$ from the oxidative burst orchestrated the plant hypersensitive disease resistance response. Cell 79, 583-593.

Mathioudakis, M. M., Veiga, R. S., Canto, T., Medina, V., Mossialos, D., Makris, A. M. and Livieratos, I. (2013): Pepino mosaic virus triple gene block protein 1 (TGBp1) interacts with and increases tomato catalase 1 activity to enhance virus accumulation. Mol. Plant Pathol. 14, 589-601.

Mittler, R. (2002): Oxidative stress, antioxidants and stress tolerance. Trends Plant Sci. 7, 405-410.

Mittler, R., Feng, X. and Cohen, M. (1998): Post-transcriptional suppression of cytosolic ascorbate peroxidase expression during pathogen-induced programmed cell death in tobacco. Plant Cell 10, 461-473.

Mittler, R., Herr, E. H., Orvar, B. L., van Camp, W., Willekens, H., Inzé, D. and Ellis, B. E. (1999): Transgenic tobacco plants with reduced capability to detoxify reactive oxygen intermediates are hyperresponsive to pathogen infection. Proc. Natl. Acad. Sci. USA 96, 14165-14170.

Niebel, A., Heungens, K., Barthels, N., Inzé, D., Van Montagu, M. and Gheusen, G. (1995): Characterization of a pathogen-induced potato catalase and its systemic expression upon nematode and bacterial infection. Mol. Plant-Microbe Interact. 8, 371-378.

Noctor, G. and Foyer, C. H. (1998): Ascorbate and glutathione: Keeping active oxygen under control. Annu. Rev. Plant Physiol. Plant Mol. Biol. 49, 249-279.

Perl, A., Perl-Treves, R., Galili, S., Aviv, D., Shalgi, E., Malkin, S. and Galun, E. (1993): Enhanced oxidative-stress defense in transgenic potato expressing tomato $\mathrm{Cu}, \mathrm{Zn}$ superoxide dismutases. Theor. Appl. Genet. 85, 568-576.

Perl-Treves, R., Nacmias, B., Aviv, B., Zeelon, E. P. and Galun, E. (1988): Isolation of two cDNA clones from tomato containing two different superoxide dismutase sequences. Plant Mo. Biol. 11, 609-623.

Roxas, V. P., Smith, R. K., Allen, E. R. and Allen, R. D. (1997): Overexpression of glutathione-S-transferase/ glutathione peroxidase enhances the growth of transgenic tobacco seedlings during stress. Nat. Biotechnol. 15, 988-991.

Sen Gupta, A., Webb, R. P., Holaday, A. S. and Allen, R. D. (1993): Overexpression of superoxide dismutase protects plants from oxidative stress. Induction of ascorbate peroxidase in superoxide dismutase-overexpressing plants. Plant Physiol. 103, 1067-1073.

Takahashi, H. Chen, Z., Du, H., Liu, Y. and Klessig, D. (1997): Development of necrosis and activation of disease resistance in transgenic tobacco plants with severely reduced catalase levels. Plant J. 11, 995-1005.

Tang, L., Kwon, S. Y., Kim, S. H., Kim, J. S., Choi, J. S., Cho, K. Y., Sung, C. K., Kwak, S. S. and Lee, H. S. (2006): Enhanced tolerance of transgenic potato plants expressing both superoxide dismutase and ascorbate peroxidase in chloroplasts against oxidative stress and high temperature. Plant Cell Rep. 25, 1380-1386.

Torres, M. A., Jones, J. D. G. and Dangl, J. L. (2006): Reactive oxygen species signaling in response to pathogens. Plant Physiol. 141, 373-378.

Tsang, E. W. T., Bowler, C., Herouart, D., Van Camp, W., Villaroel, R., Genetello, C., Van Montagu, M. and Inzé, D. (1991): Differential regulation of superoxide dismutases in plants exposed to environmental stress. Plant Cell 3, 783-792.

Van der Hoorn, R. A. L., Laurent, F., Roth, R. and De Wit, P. J. G. M. (2000): Agroinfiltration is a versatile tool that facilitates comparative analyses of Avr9/Cf9-induced and Avr4/Cf4-induced necrosis. Mol. Plant-Microbe Interact. 13, 439-446.

Vanderauwera S., Suzuki, N., Miller, G., van de Cotte, B., Morsa, S., Ravanat, J. L., Hegie, A., Triantaphylidès, C., Shulaev, V., Van Montagu, M. C., Van Breusegem, F. and Mittler, R. (2011): Extranuclear protection of chromosomal DNA from oxidative stress. Proc. Natl. Acad. Sci. U S A. 108, 1711-1716.

Wagner, U., Edwards, R., Dixon, D. P. and Mauch, F. (2002): Probing the diversity of the Arabidopsis glutathione S-transferase gene family. Plant Mol. Biol. 49, 515-532.

Willekens, H., Van Camp, W., Van Montagu, M., Inzé, D., Langebartels, C. and Sandermann, Jr. H. (1994): Ozone, sulfur dioxide and ultraviolet B have similar effects on mRNA accumulation of antioxidant genes in Nicotiana plumbaginifolia L. Plant Physiol. 106, 1007-1014. 
Willekens, H., Inzé, D., Van Montagu, M. and Van Camp, W. (1995): Catalases in plants. Mol. Breeding 1, 207-228.

Williamson, J. D. and Scandalios, J. G. (1992): Differential response of maize catalases and superoxide dismutases to the photoactivated fungal toxin cercosporin. Plant J. 2, 351-358.

Yi, S. Y., Yu, S. H. and Choi, D. (1999): Molecular cloning of a catalase cDNA from Nicotiana glutinosa L. and its repression by tobacco mosaic virus infection. Mol. Cells 9, 320-325.

Yi, S. Y., Yu, S. H. and Choi, D. (2003): Involvement of hydrogen peroxide in repression of catalase in TMV-infected resistant tobacco. Mol. Cells 15, 364-369.

Yu, T., Li, Y. S., Chen, X. F., Hu, J., Chang, X. and Zhu, Y. G. (2003): Transgenic tobacco plants overexpressing cotton glutathione S-transferase (GST) show enhanced resistance to methyl viologen. J. Plant Physiol. $160,1305-1311$. 